
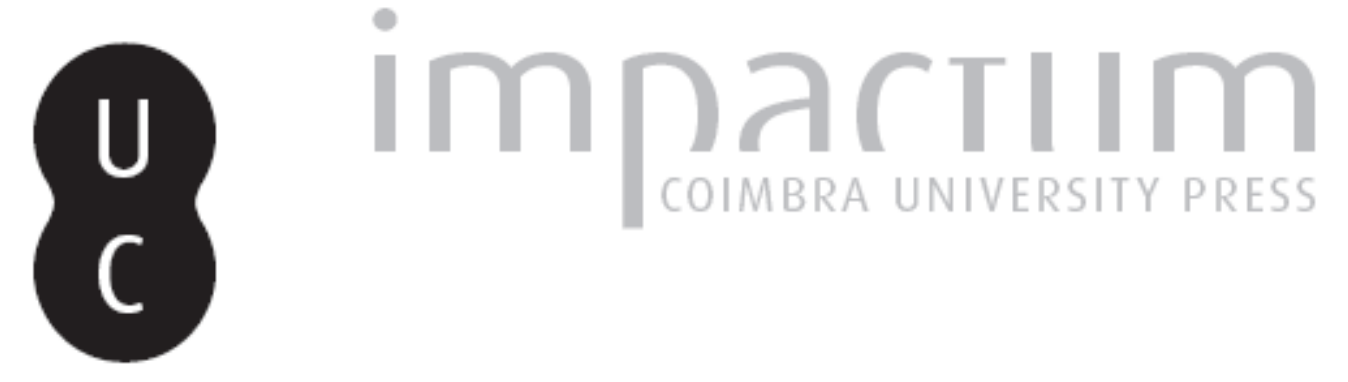

\title{
A Biblioteca Geral como parte (essencial) da Universidade
}

\section{Autor(es): $\quad$ Bernardes, José Augusto Cardoso}

Publicado por: Imprensa da Universidade de Coimbra

URL persistente:

URI:http://hdl.handle.net/10316.2/43033

DOI:

DOI:https://doi.org/10.14195/1647-8436_46_47_0

Accessed : $\quad$ 26-Apr-2023 14:06:38

A navegação consulta e descarregamento dos títulos inseridos nas Bibliotecas Digitais UC Digitalis, UC Pombalina e UC Impactum, pressupõem a aceitação plena e sem reservas dos Termos e Condições de Uso destas Bibliotecas Digitais, disponíveis em https://digitalis.uc.pt/pt-pt/termos.

Conforme exposto nos referidos Termos e Condições de Uso, o descarregamento de títulos de acesso restrito requer uma licença válida de autorização devendo o utilizador aceder ao(s) documento(s) a partir de um endereço de IP da instituição detentora da supramencionada licença.

Ao utilizador é apenas permitido o descarregamento para uso pessoal, pelo que o emprego do(s) título(s) descarregado(s) para outro fim, designadamente comercial, carece de autorização do respetivo autor ou editor da obra.

Na medida em que todas as obras da UC Digitalis se encontram protegidas pelo Código do Direito de Autor e Direitos Conexos e demais legislação aplicável, toda a cópia, parcial ou total, deste documento, nos casos em que é legalmente admitida, deverá conter ou fazer-se acompanhar por este aviso.

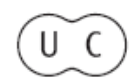




\section{BOLETIM DA \\ BIBLIOTECA GERAL DA UNIVERSIDADE DE COIMBRA}

VOL. 46/47 (2015/2016)

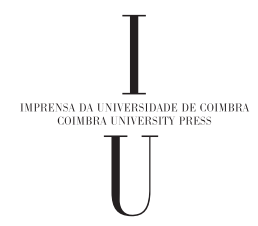




\section{A Biblioteca Geral como parte (essencial) da Universidade}

A Biblioteca Geral é parte da Universidade, cumprindo-Ihe assumir, na medida das suas possibilidades, a estratégia que esta define e aprova nos seus órgãos de governo.

Enquanto biblioteca patrimonial e universitária, deve enriquecer, preservar e divulgar, o melhor possível, o acervo que se encontra à sua guarda. É isso que fazem as boas bibliotecas do mundo, de forma dinâmica (e não já apenas passiva), recorrendo a todos os meios que têm ao seu alcance, desde os mais convencionais aos mais avançados do ponto de vista tecnológico.

Mas a Biblioteca Geral serve a Universidade no seu todo e, nessa medida, deve estar muito atenta aos seus utilizadores diretos (estudantes, professores e investigadores), criando as melhores condições para atender às suas necessidades e expectativas, envolvendo aspetos logísticos e facilitando o acesso aos documentos.

De uma Biblioteca como a nossa, à qual é apontada uma existência de mais de 500 anos, espera-se sempre mais. Espera-se nomeadamente que ela se afirme não apenas como simples equipamento, no plano em que se encontram muitos outros, mas também como instância de reflexão.

É sabido que a Universidade deve ser vista para além da simples adição das faculdades que a integram. Nessa medida, considerando as suas limitações humanas, logísticas e financeiras, a Biblioteca Geral vem procurando estimular e facilitar a circulação e a interpenetração 
de saberes. São múltiplos e variados os documentos que guarda e disponibiliza, atraindo interessados de muitas faculdades, que aqui se encontram e aprendem a conhecer-se, a respeitar-se e a colaborar mais entre si. Na Biblioteca se organizam exposições e decorrem colóquios que, por vezes, não encontram espaço fácil nas diferentes Escolas e Departamentos da Universidade. Ainda recentemente, por exemplo, a Biblioteca Geral organizou exposições documentais sobre a China, o Japão e o território de Macau, abrangendo zonas de conhecimento que não se encontram diretamente cobertas por nenhuma unidade orgânica.

Isto significa designadamente que a Biblioteca quer contribuir para que a Universidade se pense não apenas como mera adição de saberes especializados mas como a soma transformada de saberes que deve ser. Mas tem consciência plena de que também lhe cabe pensar-se a si própria, de modo a poder cumprir cada vez mais e melhor as suas funções e a enfrentar os novos desafios que se lhe colocam.

O Boletim da Biblioteca, cuja publicação agora se retoma, espera-se que com periodicidade mais regular, inscreve-se nesta exata preocupação.

Desde a sua fundação e ao longo de uma já longa história, que recobre várias designações, a publicação serviu essencialmente para acolher o pensamento dos bibliotecários que serviram a Universidade'. Quem um dia quiser abeirar-se do pensamento biblioteconómico

1 O Boletim assume-se como herdeiro do Archivo bibliográfico da Biblioteca da Universidade de Coimbra, que veio pela primeira vez a lume em janeiro de 1901, com uma periodicidade mensal, e que se manteve, sem interrupções, até maio de 1913. Logo em janeiro de 1914, viria a público com uma designação ligeiramente diferente, Boletim Bibliográfico da Biblioteca da Universidade de Coimbra. Da periodicidade mensal passar-se-ia depois, em 1917, à periodicidade anual (irregular) e de novo com uma alteração de pormenor no título (Boletim da Biblioteca da Universidade de Coimbra), até 1997. Mantendo o mesmo título, a publicação reaparece em 2010, apenas em formato eletrónico, com dois números publicados (2010 e 2014). A partir do presente volume, a designação será Boletim da Biblioteca Geral da Universidade de Coimbra. 
produzido em Portugal não pode, por isso, deixar de compulsar as coleções do nosso Boletim.

Apesar de todas as transformações ocorridas ao longo do último século, esse desígnio não perdeu atualidade nem pertinência. Ao contrário do que pode pensar-se, as bibliotecas nunca foram espaços de acomodação. Pelo contrário: basta olhar para o conjunto de transformações que nelas teve lugar nas três últimas décadas para nos apercebermos da importância dos dilemas que os bibliotecários tiveram que enfrentar e resolver. E não me refiro apenas à vertente tecnológica. Essa é e vai continuar a ser da maior importância, exigindo um constante esforço de adaptação mas também de escrutínio e prudência.

Mas há que acrescentar as mudanças de atitude que se operaram a dois outros níveis: nos utilizadores da Biblioteca (que nela esperam encontrar cada vez mais facilidades e ajudas) e nos próprios bibliotecários: se antes um bibliotecário se distinguia sobretudo pela familiaridade com os livros e pela cultura que daí resultava, justamente admirada pelos leitores que, quase sempre confinados a um saber especializado, não podiam deixar de se surpreender com quem lidava com a vastidão enciclopédica das estantes, o bibliotecário de hoje é, ele próprio também, um protagonista do saber. Não Ihe basta deter um conhecimento técnico exigente, meticuloso e transversal. É necessário apurá-lo constantemente. O desafio maior que se lhe coloca, porém, situa-se no plano dos comportamentos. Ao contrário do que sucedia até há poucos anos, o investigador que hoje chega às bibliotecas constitui o reflexo das muitas mudanças que ocorreram na Academia e na Sociedade em geral. Há evidentemente perfis que se mantêm. Em regra, porém, o pesquisador que hoje se dirige ao nosso catálogo vem mais apressado, menos predisposto para a descoberta e menos possuído pela curiosidade alargada de antigamente. 
Julgando interpretar corretamente a orientação dos tempos, o Boletim que agora se volta a publicar não é apenas de carácter técnico. Embora nele se publiquem ainda estudos dessa natureza, optámos por trazer também a lume alguns contributos relativos à missão que hoje cabe às bibliotecas universitárias. Nele têm lugar, desde logo, textos sobre bibliotecas antigas. Na Universidade em geral e nas bibliotecas de forma muito particular, os desafios do presente beneficiam muito do conhecimento esclarecido do passado. Num outro plano, dele constam também a descrição e análise de alguns acervos recentemente incorporados nas bibliotecas da Universidade de Coimbra. Ao contrário do que antes sucedia, as bibliotecas não podem limitar-se a tratar os materiais que acolhem. Têm que dar notícia da sua existência de todas as formas. Neste Boletim se acoIhem ainda textos que resultam diretamente de exposições e outras iniciativas levadas a efeito na própria Biblioteca. A ideia de que a vida de uma biblioteca se limita à disponibilização de livros numa sala silenciosa está longe de corresponder à realidade. Para além de cumprirem essa e muitas outras missões, os bibliotecários trabaIham incessantemente para atrair a atenção dos seus públicos. Nesse sentido, organizam mostras temáticas a propósito de efemérides e congressos, promovem sessões regulares para mostrar e explicar os seus tesouros e correspondem às muitas solicitações que lhe chegam da comunidade académica. Nesse sentido, a Sala do Catálogo, a Sala de São Pedro e o piso intermédio da Biblioteca Joanina constituem o espelho de uma dinâmica que constitui o reflexo honesto do que julgamos ser a nossa obrigação.

Por fim, este número duplo contém ainda um conjunto mais abrangente de reflexões que dizem respeito à Biblioteca e à Universidade sobretudo pensadas à luz da sua história.

A nossa vontade, a nossa aposta é que o presente número possa vir a assinalar uma recuperação duradoura. Não sabemos se tal será possível. Se o não for, não será por falta de vontade ou por economia de esforços. 
Pelo contrário: tal como antes sucedia e hoje ocorre ainda com mais premência, as bibliotecas necessitam de ter voz e de a fazer ouvir.

José Augusto Cardoso Bernardes

(Diretor da Biblioteca Geral) 